\title{
Microwave Ablation (MWA): Basics, Technique and Results in Primary and Metastatic Liver Neoplasms - Review Article
}

\author{
Mikrowellenablation (MWA): Grundlagen, Technik und \\ Ergebnisse in primären und sekundären Lebertumoren - \\ Übersichtsarbeit
}

Authors

Thomas J. Vogl' ${ }^{1}$, Nour-Eldin A. Nour-Eldin ${ }^{1,2}$, Renate Maria Hammerstingl', Bita Panahi ${ }^{1}$, Nagy N. N. Naguib ${ }^{1,3}$

\author{
Affiliations \\ 1 Institute for Diagnostic and Interventional Radiology, \\ Frankfurt University Hospital, Frankfurt am Main, Germany \\ 2 Department of Diagnostic and Interventional Radiology, \\ Cairo University, Faculty of Medicine, Cairo, Egypt \\ 3 Department of Diagnostic and Interventional Radiology, \\ Alexandria University Faculty of Medicine, Alexandria, \\ Egypt
}

Key words

thermal ablation, microwave ablation, hepatocellular carcinoma

received 16.01.2017

accepted 13.07.2017

Bibliography

DOI https://doi.org/10.1055/s-0043-117410

Published online: 23.8.2017 | Fortschr Röntgenstr 2017; 189:

1055-1066 @ Georg Thieme Verlag KG, Stuttgart · New York, ISSN 1438-9029

Correspondence

Prof. Thomas J. Vogl

Institut für Diagnostische und Interventionelle Radiologie, Universitätsklinikum Frankfurt

Theodor-Stern-Kai 7, 60596 Frankfurt, Germany

Tel.: ++49/69/63017277

Fax: $++49 / 69 / 63017258$

T.vogl@em.uni-frankfurt.de

\section{ZUSAMMENFASSUNG}

Hintergrund Der lokoregionale interventionelle onkologische Behandlungsansatz ist eine anerkannte Behandlungsoption bei Lebermalignomen, insbesondere beim hepatozellulären Karzinom (HCC) und oligonodulären Lebermetastasen. Material und Methode Das Hauptziel der Ablationstherapie wie Mikrowellenablation (MWA) ist es, alle Tumorzellen mittels minimal invasiver Technik unter Bildsteuerung abzutragen, während das umgebende gesunde Gewebe unter Ein- haltung eines entsprechenden Sicherheitssaumes (mindestens $5 \mathrm{~mm}$ ) geschont wird.

Ergebnisse Die Ablationstherapie erfolgt über einen perkutanen, laparoskopischen oder intraoperativen Zugang, und die Läsion wird mittels Ultraschall, MRT oder CT-Steuerung lokalisiert und überwacht.

Schlussfolgerung Ablation ist die Methode der Wahl bei oligonodulären $\mathrm{HCC} \leq 3 \mathrm{~cm}$. Die technische Erfolgsrate variiert von 88 bis $98 \%$; das progressionsfreie Überleben nach 3 Jahren liegt zwischen 27 und 91,7\%. Für die Ablation von Lebermetastasen gelten die gleichen Kriterien.

\section{Kernaussagen}

- Für optimale Ergebnisse zur MWA von Lebertumoren ist die exakte Selektion von Patienten wichtig.

- Interventionisten sollten vertraut sein mit allen Aspekten von möglichen Komplikationen und deren Therapien.

- Die MWA von Lebermalignomen scheint Vorteile gegenüber der RF-Ablation zu haben, wie z.B. kürzere Interventionszeit, weniger Schmerzen und weniger „heat sink effect“. Es fehlen jedoch Daten randomisierter Studien.

\section{ABSTRACT}

Purpose The locoregional interventional oncological treatment approach is an accepted modality for liver neoplasms, especially for hepatocellular carcinoma (HCC) and oligonodular liver metastases.

Materials and Methods The main aim of ablation therapies like microwave ablation (MWA) is to eradicate all malignant cells in a minimally invasive technique under imaging guidance while preserving the healthy tissue with a sufficient safety margin (at least $5 \mathrm{~mm}$ ) surrounding the ablated lesion. Results Ablation therapy can be performed via a percutaneous, laparoscopic or intraoperative approach under ultrasound, MRI or CT guidance for adequate localization and monitoring of the ablation process.

Conclusion Ablation is the method of choice for oligonodular HCCs $\leq 3 \mathrm{~cm}$. The technical success rate varies from $88 \%$ to 
$98 \%$ and progression-free survival (PFS) at 3 years from $27 \%$ to $91.7 \%$. The same criteria apply to the therapy of liver metastases.

\section{Key Points}

- Careful selection of patients proves to be essential for optimum results of MWA

- Interventionists should be familiar with all aspects of complication and rapid assessment of imaging methods in order to evaluate induced damage by thermal ablation
- MWA seems to have some advantages over radiofrequency ablation, like shorter ablation time, less pain, less heat sink effect; however, scientific proof is needed

\section{Citation Format}

- Vogl TJ, Nour-Eldin A, Hammerstingl RM et al. Microwave Ablation (MWA): Basics, Technique and Results in Primary and Metastatic Liver Neoplasms - Review Article. Fortschr Röntgenstr 2017; 189: 1055-1066

\section{Introduction}

Hepatocellular carcinoma (HCC) is the third most common organspecific cause of cancer-related mortality in the world with an average survival rate of less than six months if untreated, and a five-year survival of only 5-9\% from the time of diagnosis [1]. Furthermore, the liver is the most common site of distant metastases in patients with colorectal cancer with a cumulative incidence rate of up to $50 \%$. Surgical techniques like resection or transplantation are still considered the gold standard for the treatment of primary and secondary liver cancer. However, in more than $75 \%$ of cases surgical resection is not possible [2]. The same applies to systemic chemotherapy. Different alternative interventional modalities for the treatment of unresectable liver tumors are available. In interventional oncology two different therapeutic approaches can be used for the treatment of liver malignancies: first, transarterial procedures with administration of chemotherapeutic agents such as transarterial chemoperfusion (TACP), transarterial chemoembolization (TACE) or transarterial embolization (TAE) or radioactive material such as selective internal radioembolization (SIRT); second, thermal ablation techniques such as radiofrequency ablation (RFA), microwave ablation (MWA) and laser-induced interstitial thermotherapy (LITT) as well as irreversible electroporation (IRE) and cryotherapy. These are potential minimally invasive treatment modalities especially in early-stage HCC and oligonodular metastases (three or less lesions), particularly in non-resectable liver lesions or if the patient is not a candidate for liver transplantation or is in poor general condition [3].

This paper reviews the evidence supporting the use of MWA in the treatment of HCC and hepatic metastases. Furthermore, basic principles, theoretical background, tools and techniques, technical problems, and the latest MWA protocols will be discussed. The advantages, limitations, and technical considerations of MWA treatment will be provided.

\section{Techniques \& Methods}

\section{Background and definition}

Since the early 1980s, local therapies have emerged for the treatment of non-resectable hepatic tumors [4]. Tumor ablation is defined as a direct application of non-energy (chemical) or energybased (thermal and non-thermal) modalities via applicator (probes, electrodes and antennae) that eradicate or destroy a tumor either through thermal (heat or cold) or non-thermal mechanisms [4]. Currently the most established thermal ablative techniques are RFA, MWA, LITT and cryotherapy ( $\downarrow$ Table $1-3$ ). $[2,5]$.

Microwave coagulation was developed in the early 1980s during hepatic resection in order to achieve hemostasis [6] and has substantially changed the field of thermal ablation in interventional oncology. Thus the term "microwave ablation" should replace the less succinct terms "percutaneous microwave coagulation therapy" and "microwave coagulation therapy" [4, 7]. In recent years, numerous different devices and generators with higher energies have been developed for MWA in order to increase the size of ablation zones, to achieve larger ablation margins and to decrease local tumor progression.

In contrast to RFA, studies with MWA have shown advantages in large tumors, in locations around large vessels and in highly perfused areas, where RF energy is limited. Microwave energy produces faster heating and higher temperatures resulting in larger areas of necrosis compared to RFA [8]. Moreover in MWA a better demarcated ablation zone can be produced [9].

\section{Direct Comparison of MWA and RFA}

\section{Applicators, Generators \& Mechanism}

MWA devices consist of three basic parts: generator, flexible cable and antenna. The antenna which is used in MWA is often referred to as a "needle" or other nonspecific terms, but generally the terms "applicator", "antenna" and "probe" should be used for energy-based devices [4].

Both RFA and MWA are thermal ablation techniques that make use of electromagnetic energy, causing the rotation of water molecules. Different energy sources have been employed in order to provide the necessary heat for inducing coagulation necrosis [10]. RFA ranges from $300 \mathrm{MHz}$ to $300 \mathrm{GHz}$, whereas MWA generators currently allow only two frequency spectrums, namely $915 \mathrm{MHz}$ and $2.45 \mathrm{GHz}$. MWA devices function within the RF spectrum and can technically be defined as a subset of RFA. Generally heat is dissipated centrifugally around the probe tip. When adequate heat is generated throughout, tumor cells around the antenna tip can be destroyed effectively by denaturation of intracellular proteins and cell membranes through dissolution and melting of lipid bilayers. Depending on the energy deposition, even ablation zones $>5 \mathrm{~cm}$ can be achieved. Intratumoral temperatures can be measured 
- Table 1 Technical success in MWA (TS: technical success, US: ultrasound).

- Tab. 1 Technischer Erfolg bei der MWA (TS: technischer Erfolg, US: Ultraschall).

\begin{tabular}{|c|c|c|c|c|c|}
\hline author & year & $\begin{array}{l}\text { number of } \\
\text { patients }\end{array}$ & pathology & technique & technical success (TS) \\
\hline Alexander es et al. [22] & 2015 & 64 & $\begin{array}{l}\text { different hepatic } \\
\text { malignant tumors }\end{array}$ & MWA & TS: $95 \%$ \\
\hline Ai-Xue Sun et al. [45] & 2015 & 182 & $\begin{array}{l}\text { single medium-sized } \\
\mathrm{HCC}\end{array}$ & MWA & TS: $93 \%$ \\
\hline Ginsburg $\mathrm{M}$ et al. [43] & 2015 & 89 & $\mathrm{HCC}$ & MWA vs. RF & $\begin{array}{l}\text { TS in TACE+RFA: } 80.4 \% \\
\text { TS in TACE+MWA: } 76.6 \%\end{array}$ \\
\hline Zhang L et al. [39] & 2013 & 155 & $\mathrm{HCC}$ & $\begin{array}{l}\text { RF vs MW in HCC } \\
\leq 5 \mathrm{~cm}\end{array}$ & TS $83.4 \%$ in RF, $86.7 \%$ in MWA \\
\hline Li M et al. [51] & 2012 & 89 & $\begin{array}{l}96 \text { hepatic lesions } \\
\text { adjacent to diaphragm }\end{array}$ & US-guided MWA & $\begin{array}{l}\text { TS: } 94.8 \% \text { in hepatic lesions } \\
\text { adjacent to diaphragm }\end{array}$ \\
\hline Liu F et al. [40] & 2011 & 107 & $\mathrm{HCC}$ & $\begin{array}{l}\text { contrast-enhanced } \\
\text { US-guided MWA }\end{array}$ & TS: $98.13 \%$ \\
\hline Lu MD et al. [53] & 2005 & 102 & $\mathrm{HCC}$ & MWA vs. RF & $\begin{array}{l}\text { TS for MWA: } 95 \% \\
\text { TS rate for RFA: } 93 \%\end{array}$ \\
\hline
\end{tabular}

- Table 2 MWA complications in large case studies.

- Tab. 2 Komplikationen bei der MWA in großen Fallstudien.

\begin{tabular}{|c|c|c|c|c|c|}
\hline author & year & $\begin{array}{l}\text { number of } \\
\text { patients }\end{array}$ & pathology & & complication \\
\hline Ai-Xue Sun et al. [45] & 2015 & 182 & single medium-sized HCC & MWA & major complication: $2.7 \%$ \\
\hline Wang XH et al. [50] & 2012 & 898 & 1111 primary liver tumors & MWA & $\begin{array}{l}2 \text { deaths, } 27 \text { major complications } \\
\text { including } 10 \text { cases of tumor cell seeding. } \\
\text { Cooled-tip MWA is a relatively low-risk } \\
\text { and effective minimally invasive treat- } \\
\text { ment method in primary liver cancer }\end{array}$ \\
\hline Li M et al. [51] & 2012 & 89 & $\begin{array}{l}96 \text { hepatic lesions } \\
\text { adjacent to diaphragm }\end{array}$ & $\begin{array}{l}\text { US-guid- } \\
\text { ed MWA }\end{array}$ & $\begin{array}{l}\text { no major complications } \\
\text { safe for treatment of hepatic lesions } \\
\text { adjacent to diaphragm }\end{array}$ \\
\hline Livraghi T et al. [52] & 2012 & 736 & 1037 hepatic lesions & MWA & $\begin{array}{l}\text { major complication rate: } 2.9 \% \\
\text { minor complication rate: } 7.3 \% \\
\text { MWA is a safe method for the treatment } \\
\text { of hepatic lesions }\end{array}$ \\
\hline
\end{tabular}

with separately placed thermocouple probes or the antenna itself (depending on the MW system). Immediate coagulation will occur at temperatures from $60-100^{\circ} \mathrm{C}$ and vaporization and carbonization at temperatures of more than $110^{\circ} \mathrm{C}[10]$. In successful ablation, the temperature should be homogeneously increased to about $50-60^{\circ} \mathrm{C}$ for at least $5 \mathrm{~min}$. High temperatures should be avoided in order to lower the vaporization and carbonization effect.

Vaporization is defined as a phase transition from the solid liquid phase to vapor as a gas, visible in CT or ultrasound. Carbonization is defined as the conversion of a solid phase into carbon, preventing the regional distribution of heat.
Different data have been published regarding the comparison of MW frequencies. Sun Y. et al. reported that the $915 \mathrm{MHz}$ protocol has a greater tissue penetration depth and a larger ablation zone at the same power than the $2,450 \mathrm{MHz}$ protocol due to the longer wavelength. Furthermore, the back heating effect was reported to be lower due to fewer reflected waves at the lower frequency [11].

It was demonstrated that there is a relationship between tissue temperature and tissue water content. Therefore, significant water loss in the tissue up to $3 \mathrm{~mm}$ from the edge of the applicator is detectable after only $1 \mathrm{~min}$. This illustrates the volume heating effect that can be seen in MWA. Microwaves spread from the 
- Table 3 Recurrence rate in liver tumors treated with MWA.

- Tab. 3 Rezidivrate bei mit MWA behandelten Lebertumoren.

\begin{tabular}{|c|c|c|c|c|c|}
\hline author & year & $\begin{array}{l}\text { number of } \\
\text { patients }\end{array}$ & pathology & technique & recurrence rate \\
\hline VOGL T] et al. [38] & 2015 & 53 & $\mathrm{HCC}$ & RF vs. MW & $\begin{array}{l}\text { for } 3,6,9 \text { and } 12 \text { months, } 6.3 \%, 3.1 \% \text {, } \\
3.1 \% \text { and } 3.1 \% \text { vs. } 0 \%, 5.6 \%, 2.8 \% \text { and } \\
2.8 \% \text {, respectively. }\end{array}$ \\
\hline Alexander ES et al. [22] & 2015 & 64 & $\begin{array}{l}\text { different malignant } \\
\text { hepatic tumors }\end{array}$ & MWA & $\begin{array}{l}\text { no significant relationship between } \\
\text { tumor size, recurrence time and } \\
\text { treatment time } \\
\text { ecurrence after } 1 \text { year, } 39.8 \% \text { for HCC, } \\
45.7 \% \text { for CRC and } 70.8 \% \text { in other cases }\end{array}$ \\
\hline Ai-Xue Sun et al. [45] & 2015 & 182 & $\begin{array}{l}\text { single medium-sized } \\
\mathrm{HCC}\end{array}$ & MWA & $\begin{array}{l}51 \% \text { recurrence-free at } 1 \text { year, } 36 \% \text { at } \\
2 \text { years } \\
\text { and } 27 \% \text { at } 3 \text { years }\end{array}$ \\
\hline Groeschl RT et al. [54] & 2014 & 450 & $\begin{array}{l}\text { different malignant } \\
\text { hepatic tumors }\end{array}$ & MWA & $\begin{array}{l}\text { local recurrence rate: } 10 \% \\
\text { ^size } \geq 3 \mathrm{~cm} \text { associated with worse } \\
\text { prognosis }\end{array}$ \\
\hline Li M et al. [51] & 2012 & 89 & $\begin{array}{l}96 \text { hepatic lesions } \\
\text { adjacent to diaphragm }\end{array}$ & $\begin{array}{l}\text { ultrasound- } \\
\text { guided MWA }\end{array}$ & local tumor progression rate: $18.8 \%$ \\
\hline
\end{tabular}

applicator through the tissue and heat the surrounding tissue as the wave attenuates. This leads to direct deposition of energy in a larger tissue volume than seen during RFA [12]. Since the electromagnetic energy requires no direct current flow, it overcomes the limitations of RFA regarding carbonization and evaporation of the tissue. In addition, the drain of energy on large vessels (so-called heat-sink effect) is less evident, ruling out the proximity of tumors to adjacent vessels as a contraindication [13]. In comparison to RFA, MWA is faster, shows more uniform tissue penetration and has a more predictable ablation zone on CT scans during the ablation procedure. Due to higher temperatures in the tumor tissue and shorter treatment times, the treatability in cystic lesions is also improved using MWA. Other tissue properties like thermal conductivity, electrical conductivity (for RFA), tissue elasticity or fibrosis, tissue water content and permittivity affect the induced ablation zone in thermal ablation [4].

Cooled applicators also affect the procedure time and the result. In an ex vivo bovine liver study, it is reported that large ablation zones can be achieved with a high-power system $(180 \mathrm{~W})$ with an internally cooled applicator within a short ablation time of 5 minutes. With a non-cooled applicator in a lowpower system a large ablation zone can be achieved when the ablation time is prolonged [14].

Two studies compared the effectiveness of MWA and multipolar RFA in porcine livers using a pair of simultaneously powered internally cooled shaft antennas. They showed that ablation zones for MWA were significantly larger for four different power settings. Also, the temperature increase to $50{ }^{\circ} \mathrm{C}$ in all MWA power settings was significantly faster than in both multipolar RFAs, and MWA had similar efficacy to RFA in local tumor control [15]. It should be considered that MWA could obviously create larger ablation zones. However, it could not be proved that this results in better local tumor control or local tumor control rates. Thus, MWA might be advantageous due to reduced ablation times and the lower cooling effect of neighboring vessels. For patients the reduced pain due to the shorter ablation time is considered advantageous [16].

MWA can be performed with a single or multiple applicators. For single applicator ablation, only one generator is employed. For triangular and spherical ablation, each applicator should be connected to one of three independent generators. The major disadvantage of techniques using multiple antennas is the greater difficulty in placing all antennas in the correct position, which requires greater operator skills with respect to ultrasound or CT guidance and mental reconstruction of three-dimensional structures [17]. The synchronicity of the microwaves is important for performing ablations with more than one applicator. In multiple antennas with synchronous energy deposition, constructive interference occurs and makes greater energy deposition, which leads to a larger but partially irregularly induced ablation zone. Newly developed techniques for high-energy MWA even improve the outcome of thermal ablation by inducing more spherical necrosis volumes.

\section{Indication for MWA}

Tumor ablation indications are divided into either a curative or palliative intention. In a curative ablation the goal is the complete eradication of all tumor cells in order to produce a tumor-free condition. In a palliative intention the main goal of MWA or RFA is to ablate a sufficient portion of the index tumor in order to achieve symptom relief. The aim of debulking is the reduction of 
tumor burden or controlling disease progression. This is of great importance, in particular, for pain reduction due to capsular or intestinal tumor infiltration or reduction of symptoms from metastatic neuroendocrine tumors [4].

The Barcelona Clinic Liver Cancer (BCLC) staging and treatment strategy has been widely endorsed as the optimum treatment option for HCC liver cancer. One of the key aspects in patient management is the optimum timing for systemic treatment initiation and for declaring tumor progression and/or treatment failure. The treatment strategy for the effective treatment of HCCs with the usual priority selection is from very early stage HCC (resection, transplantation, ablation) to intermediate stage (TACE) to advanced stage (sorafenib). For very early stages of HCC, BCLC stage 0 (single lesion $\leq 2 \mathrm{~cm}$, Child-Pugh A, PSO 0), ablation treatment of the lesion is the recommended first-line treatment option for patients who are not potential candidates for liver transplantation. For early stages of HCC (BCLC stage A), surgical resection, liver transplantation and ablation are the recommended lines of treatment as defined by the BCLC staging system and based on specific selection criteria for each option. Although resection can be performed in some of these patients with advanced liver disease, the mortality is higher and liver transplantation or ablation could be more beneficial. Although recommendations of BCLC and the guidelines of the American Association of the Study of the Liver Disease (AASLD) refer only to RFA, studies have proved that MWA has comparable local control rates and similar survival rates to RFA [16].

The treatment algorithm established by the AASLD recommends local treatment for early-stage $\mathrm{HCCs}(\leq 3 \mathrm{~cm}$ in size and $\leq 3$ lesions) or early-stage HCCs $(\leq 2 \mathrm{~cm})$ with complications such as portal hypertension. However, for early-stage HCCs (single or $\leq 3$ lesions and $\leq 3 \mathrm{~cm}$ ) without complications like portal hypertension, cirrhosis or high bilirubin, liver resection should be considered as the best treatment option. Total tumor volume $>70 \%$ of the liver volume, multiple tumor nodules, high extrahepatic tumor burden, clinical evidence of liver failure, such as massive ascites, hepatic encephalopathy or other organ failure, severe blood coagulation dysfunction including prothrombin time longer than $30 \mathrm{~s}$, prothrombin activity below $40 \%$, platelet count below 30,000 , acute or active inflammatory and infectious lesions in other organs are considered as absolute contraindications [18]. Metallic materials like surgical clips and pacemakers are not contraindications for MWA. In the treatment of non-HCC liver malignancies like liver metastases, in general a tumor size of more than $5 \mathrm{~cm}$ or more than five liver lesions or considerable ascites can be considered as absolute contraindications for interventional MWA. A tumor location close to vital structures such as the bowel, gallbladder, major bile ducts or major blood vessels; active infection; cholestasis; bile duct dilatation or previous anastomotic surgery might be considered as relative contraindications [19]. The European Society for Medical Oncology (ESMO) recommends treating oligometastatic disease with a strategy of local ablative therapy, the spectrum of which includes surgical R0 resection, percutaneous ablation and intra-arterial therapies, the choice of treatment being left to the multidisciplinary team. [20]. Microwave ablation has been used to treat hepatic metastases from solid tumors, e. g. colorectal cancer, breast cancer, lung cancer and car- cinoid tumors [20-22]. Compared to surgery, microwave ablation can provide comparable results in treating liver metastases from colorectal cancer. A study by Shibata et al. compared the survival between surgical resection and MWA of colorectal cancer liver metastases. The 1-, 2-, and 3-year survival rates and mean survival times were $71 \%, 57 \%, 14 \%$, and 27 months, respectively, in the microwave group, whereas they were $69 \%, 56 \%, 23 \%$, and 25 months, respectively, in the hepatectomy group [23]. Complete tumor ablation near major vessels can be difficult to achieve. In rare cases MWA might be performed in order to debulk hepatic tumors and reduce local pain or symptoms from compressing neighboring structures.

\section{Procedure}

\section{Patient preparation and monitoring}

Before the start of therapy, the patient's record should be discussed in an interdisciplinary tumor board including experts from hepatobiliary surgery, hepatology and oncology. Written informed consent should be obtained before treatment. Patients should be informed about alternative therapy modalities like surgery, radiooncological therapy, possible complications and side effects. Preinterventional blood tests should include routine blood counts, WBC, RBC count and PLT, liver function and kidney tests. Depending on the underlying disease coagulation parameters are essential: thrombocytes should be equal to or more than 30,000 .

Pre-ablation imaging like CT or preferably MRI should be performed (should not be older than 1 month). Furthermore, the medical history and complete drug history of the patient should be obtained, especially for previous treatment protocols.

Patient should fast for at least 6 hours before ablation. Percutaneous MWA is also feasible as an in- and outpatient procedure under local anesthesia and analgosedation with at least 6 hours of observation after the procedure. Depending on the clinical status of the patient, a one night hospital stay is preferable and mostly practiced [24]. Some groups focus on outpatient procedures [25].

\section{MWA technique}

For the performance of MWA, various interventional approaches (percutaneous, laparoscopic or intraoperative) and methods of guidance (CT, MRI and ultrasound) are available. Generally one, rarely more antennas are placed directly into the tumor. For ablation, an electromagnetic microwave is emitted. Each generator is capable of producing different powers, for example 45 to $100 \mathrm{~W}$ at a frequency of $915 \mathrm{MHz}$ or $2450 \mathrm{MHz}$, depending on the device type [11]. Different protocols for the temporal course of the energy are in use. One protocol starts the ablation procedure first with low energy and gradually increases the power, while monitoring the ablation zone and possible complications.

Adequate monitoring of oxygen level via pulse oximetry should be provided during intervention. Blood pressure should also be measured before and after treatment.

In order to devascularize the hepatic malignancy and to reduce the bleeding risk, neoadjuvant transarterial lipiodol-based embo- 
lization (TACE) can be performed before ablation. In addition, transarterial lipiodol embolization can help to mark the lesion for the planned ablation.

To decrease potential damage to nearby structures and to minimize complications, a "hydrodissection" technique might be used. In this case $0.9 \%$ saline or $5 \%$ dextrose in water is injected between the targeted lesion and adjacent organs like the intestine, kidney or vessels in order to protect them from possible thermal damage. The visibility of the fluid can be improved on CT by using a 1:50 ratio of iodinated contrast in the fluid. Other available methods are air or carbon dioxide instillation, balloon placement and leveraging of the ablation zone away from vulnerable structures using the antenna [26-29]. In a prospective study, artificial ascites as separation in ultrasound-guided percutaneous MWA was used in 36 hepatic tumors adjacent to the gastrointestinal tract. The separation success rate and technical effectiveness of MWA were reported to be $88.9 \%$ and $96.9 \%$, respectively [30]. Recently in experimental studies, a thermoprotective gel was successfully injected [26, 27].

Accurate and reliable methods for near real-time imaging assessment during ablation are essential to determine the adequacy of therapy in order to prevent under- or overtreatment of a lesion [31]. Using ultrasound monitoring during thermal ablation, a hyperechogenic focus can often be seen surrounding the distal part of the applicator, which is caused by microbubbles and gas released from the heated tissue. This does not correlate with adverse tissue coagulation. The presence of gas bubbles in the liver parenchyma during MWA can affect ultrasound evaluation by overestimating the size of the ablated areas. This phenomenon will often disappear completely within $1 \mathrm{~h}$ after ablation [10]. In contrast, positioning an MWA antenna and monitoring via CT allow precise online visualization of the vaporization process and early detection of possible complications, like bleeding or pneumothorax.

\section{When should thermal ablation be interrupted?}

In the case of a major complication during the procedure including massive bleeding, severe pain, severe pneumothorax or perforation of adjacent organs, the procedure should be stopped immediately. In severe bleeding, an immediate CT angiography scan should be performed, and in case of arterial hemorrhage, interventional angiography and embolization should be initiated. In the case of minor complications like pneumothorax or minimal perihepatic bleeding, the patient's vital functions must be monitored.

After the procedure, the puncture site will be covered with a sterile dressing and the patient should be observed for a minimum of 6 hours. During this period regular assessment of the patient's vital signs and pain should be performed.

A contrast-enhanced CT or MRI examination should be performed within 24 hours after treatment to determine the volume of ablation and evaluate if the residual tumor requires retreatment. Although there are no scientific data proving this concept, it is practiced in many institutions.

\section{Post-procedural imaging}

Postprocedural imaging findings can be considered as a rough guide to the success of ablation therapy because microscopic foci of residual disease cannot be detected with standard imaging. "Ablation zone" is used to describe the radiologic region or zone of induced treatment effect in the area of gross tumor destruction, which is visualized by imaging. In pathologic findings a central "white zone" of coagulation induced in most thermal therapies is generally accepted to represent coagulated tissue. This is surrounded by a variable "red zone" of hyperemia, which is best documented on MRI [17]. On delayed contrast images, peripheral rim enhancement (e.g. for CT $<20 \mathrm{HU}$ ), which often surrounds the region of coagulation, can be identified. The rim usually indicates an inflammatory reaction due to thermally damaged cells [10]. This can be considered pseudoenhancement or alternatively represent minimal enhancement from leaky capillaries at the treatment margin [4]. A bulky irregular rim at the edge of a treatment site is the most common appearance of an incompletely treated lesion [10].

Hence, after the ablation procedure, the following different imaging findings are identified: zones with decreased perfusion and changes in signal intensity on MRI, higher echogenicity on US, higher attenuation on CT or tracer uptake on PET [32].

The gross pathologic appearance of treated tissue should be referred to as coagulation-like pathologic findings associated with high-temperature thermal injury. As the ablation actively leads to tumor destruction, the more generalized term "coagulation" is preferred to "coagulative necrosis", as it has a well-defined meaning in pathology including the absence of visible nuclei within the dead cells. The term "lesion" should not be used for ablation zone, as ablation zone refers to both the ablated area as well as the underlying tumor to be ablated [4].

MRI follow-up findings should be evaluated according to the presence or absence of gadolinium enhancement in the treated region. At the 3-month follow-up, the ablation area appears to be homogenous, while the MRI examination within 3 days after ablation shows heterogeneous alteration on unenhanced T1- and T2-weighted images and diffusion-weighted sequences, which can be caused by focal hemorrhage.

Most likely an uneven evolution of the necrotic area and the host response to thermal damage lead to a change in the variability of signal intensity throughout the ablated region. In gadolinium-enhanced images, a thin rim of enhancement after treatment is usually detected ( $\mathbf{F i g . 1}$ ) and, similar to CT scans on which the rim appears bulky, can represent a residual tumor [10].

Although the gross extent of induced coagulation can be identified on imaging, the accuracy is limited by both spatial and contrast resolution to approximately $2-3 \mathrm{~mm}$ depending on the imaging modality used.

At 6 - 12 months after ablation, regression of the ablation zone is detected. Most commonly, a less than $20 \%$ reduction in volume of the non-enhanced peripheral rim is documented [10]. There is a lack of consensus on a standard follow-up strategy for follow-up imaging. The most common approaches include contrast-enhanced imaging (US, CT, MRI, or PET-CT) within 1 day of the initial ablation to determine whether additional ablation therapy is 

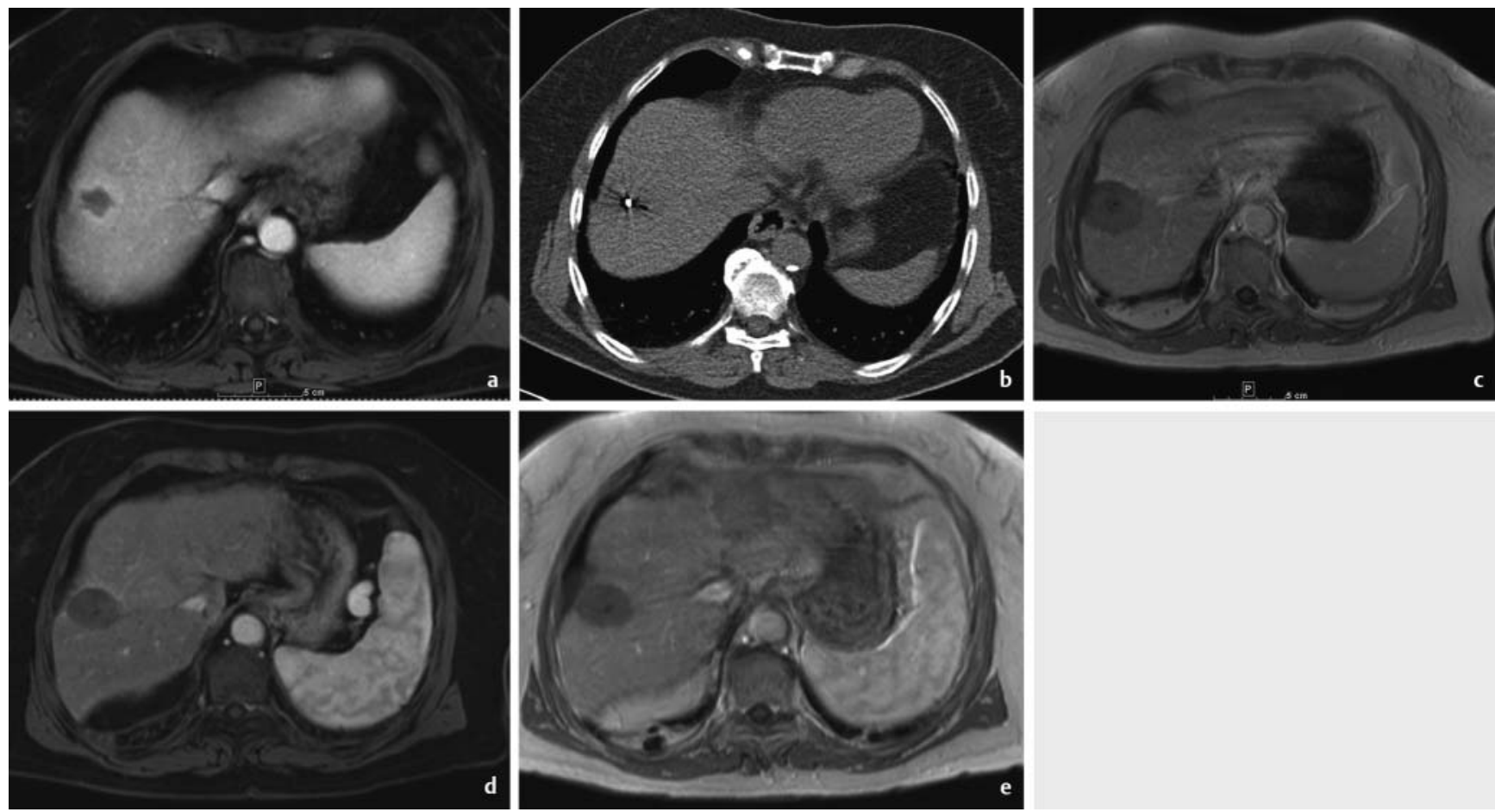

- Fig. 1 70-year-old woman with pathologically proven HCC/CCC mixed tumor. After three courses of TACE, the size of the tumor could be reduced from $24 \mathrm{~mm}$ to $19 \mathrm{~mm}$. However, a major safety rim was necessary in order to achieve A0 ablation. a Gradient-echo MR sequence T1 VIBE DIXON TRA TR/TE 6.69/2.39, gadolinium-enhanced. Verification of the necrotic part of the tumor central in the hyperenhanced rim surrounding the tumor after chemoembolization. $\mathbf{b}$ CT-guided navigation with positioning of the antenna tip (Emprint ${ }^{\mathrm{TM}}$, Covidien) in the central part of the tumor. c T1w contrast-enhanced tra TR/TE 6.69/2.39. Follow-up MRI 24 hours after ablation demonstrates a spherical ablation zone of $55 \mathrm{~mm}$ in size with minimum peripheral rim enhancement. $\mathbf{d}$ Gadolinium-enhanced MR imaging follow-up (TR/TE 500/17) demonstrates the reduction of the ablation volume and complete A0 ablation after 3 months. e Further reduction in size and homogenization after 6 months. T1 sequence TR/TE $6.69 / 2.39$.

- Abb. 170 jährige Frau mit pathologisch nachgewiesenem HCC/CCC (gemischter Tumor). Nach 3 TACE-Sitzugen konnte der Tumor von 24 mm auf $19 \mathrm{~mm}$ reduziert werden. Ein größerer Sicherheitssaum war jedoch notwendig, um eine A0 Ablation zu erreichen. a Gadolinium-verstärkte Gradienten-Echo MR-Sequenz T1 VIBE DIXON TRA TR/TE 6.69/2.39. Verifikation des nekrotischen Tumoranteils zentral im hyperverstärkten Rand um den Tumor post Chemoembolisation. b CT-gesteuerte Navigation mit Positionierung der Nadelspitze (Emprint $\mathrm{T}^{\mathrm{TM}}$, Covidien) im Zentrum des Tumors. c T1w Kontrastverstärkte tra TR/TE 6.69/2.39. Follow-up 24 Stunden nach Ablation zeigt eine kugelförmige Ablationszone von 55 mm mit minimalem peripherem Rand-Enhancement. d Gadolinium-verstärktes MRT Follow-Up (TR/TE 500/17) zeigt eine Reduktion des Ablationsvolumens und eine vollständige A0 Ablation nach 3 Monaten. e Weitere Größenreduktion und Homogenisierung nach 6 Monaten. T1 sequence TR/TE $6.69 / 2.39$.

required. In many centers this evaluation is even performed on the day of the initial procedure, every 1-4 months thereafter and at longer intervals over the course of time, depending on imaging findings, underlying tumor and patient risk factors.

\section{Assessment of Technical Effectiveness}

When the ablation zone completely overlaps or encompasses the target tumor plus an ablative safety margin, it can be classified as "technically successful" [4]. An appropriate safety margin of about 5 to $10 \mathrm{~mm}$ of apparently healthy tissue surrounding the lesion and beyond the borders of the tumor is necessary in order to achieve complete tumor destruction. Thus, possible micro-metastases or microscopic foci can also be destroyed and the risk of local recurrence is minimized. However, data to support precise recommendations regarding the ideal margin size are currently lacking [33, 34]. Extension of the desired or intended ablative margin is not always necessary, as this can increase the risk of complications, but an insufficient ablative margin is defined as an independent significant risk factor for local tumor progression [8, 33].

Residual microscopic malignant foci, particularly at the periphery of a treated lesion with its normally high blood perfusion, can continue to grow and then lead to therapy failure. Therefore longterm imaging follow-up plays a significant role in documenting successful ablation [10].

\section{Side effects and complications}

According to the SIR classification (Society of Interventional Radiology), a major complication is an event that leads to substantial morbidity and disability and increases the level of care, or results in hospital admission, or significantly lengthens the hospital stay (classifications $\mathrm{C}-\mathrm{E}$ ), also including any case in which blood transfusion or interventional drainage procedure is needed. All other complications like small bleeding or hematoma are considered 
minor. Several complications such as pneumothorax or tumor seeding can be considered either a major or minor complication, depending on their severity [35].

Undesired consequences of the ablation procedure that commonly occur include pain, post-ablation syndrome (PAS), asymptomatic pleural effusions and minimal asymptomatic perihepatic (or renal) fluid or blood collections. Furthermore, imaging evidence of asymptomatic minimal thermal damage of adjacent structures without other "collateral damage" can be expected. For example, when the ablation zone extends beyond the liver capsule and includes small portions of the diaphragm, this should not be considered a major complication, as these side effects do not require an increased level of care and follow-up control or admission to the hospital.

During ablation procedures, pain is a relatively common complication. Patients might experience pain even with an appropriate local anesthesia technique. Moreover, in many patients grade 1 to 2 pain can persist for several days, even for 1 to 2 weeks after ablation depending on the organ site. PAS is a transient, usually self-limiting symptom with low-grade fever $\leq 37.8$, nausea, vomiting, residual soreness of the treated area and malaise for up to one week. Its duration depends on the tumor volume, the volume of necrosis produced and the overall condition of the patient. If relatively large areas of the liver are ablated, the syndrome may persist for 2 to 3 weeks. Pain reduction is usually fast and occurs within the first 24 hours in some patients and during the first week in most of patients. After ablation of small tumors, patients are unlikely to experience PAS at all. For large tumors the incidence of PAS is higher, hence it might be feasible to prophylactically use antipyretic medication and a pain killer. In almost all PAS cases, symptomatic treatment with antipyretic medication or pain killer is sufficient. Pleural effusion may also occur.

Bile duct damage, severe bleeding, infection of ablation cavity which can lead to liver abscess, colonic perforation, and tumor cell seeding are the most serious complications. Post-procedure bleeding and tumor cell seeding can be prevented by attempting to obliterate damaged vessels and tumor cell destruction via heating of the puncture channel during withdrawal of the probe with microwave [7].

Compared to RFA, the most frequent complication of MWA is bleeding, which rarely requires transfusion ( $<1 \%)$. Furthermore, pneumothorax ( $<1 \%$ ), liver abscess (about $1 \%$ ) and injury of bile or gallbladder vessels (<1\%) were reported. Overall complication rates are reported to be around 3-7\%, when using a non-cooled shaft antenna. Moreover, multiple MWA sessions are associated with a higher rate of major complications $[13,36]$.

A survey including 16 studies and 2062 patients in which MWA was compared to RFA for hepatic lesions using meta-analytical techniques showed significantly better 6 -year overall survival rates for MWA than RFA (odds ratio: $1.64,95 \%$ confidence interval: $1.15-2.35$ ) in 3 of 16 articles. Moreover, the 1 - 5-year overall survival, disease-free survival, local recurrence rate, and adverse events showed comparable results. Regarding safety and efficacy outcomes, MWA and RFA can be currently considered effective local hepatic therapy techniques [37].

\section{Results}

\section{MWA results in HCC}

For the evaluation of MWA results in treating HCCs, the local and tumor control rate, overall survival (OS), mean and medium survival rate, as well as PFS are essential parameters. For the treatment of HCCs, clinical guidelines categorize ablation therapies not only as equal to surgery but even better than surgery in small or very small HCCs (oligonodular tumors $\leq 3 \mathrm{~cm}$ ). The main reason for this recommendation is the fact that ablation leads to much less loss in the normal liver parenchyma compared to surgical resection.

The therapeutic response of MWA in HCCs in 53 patients was evaluated and compared in a retrospective study. Complete local tumor control was documented in $84.4 \%$ of lesions treated with RFA and in $88.9 \%$ of lesions treated with MWA. However, in both groups technical success was achieved in lesions $<2 \mathrm{~cm}$. The recurrence rates at 3, 6, 9 and 12 months were $6.3 \%, 3.1 \%, 3.1 \%$ and $3.1 \%$ in RFA vs. $0 \%, 5.6 \%, 2.8 \%$ and $2.8 \%$ in MWA, respectively. The PFS rates at 1,2 , and 3 years were $96.9 \%, 93.8 \%$, and $90.6 \%$, respectively for patients treated with RFA and $97.2 \%$, $94.5 \%$ and $91.7 \%$, respectively, for patients treated with MWA [38].

In a retrospective study Zhang $L$ et al. [39] compared the therapeutic efficacy of percutaneous RFA to MWA in HCCs $\leq 5 \mathrm{~cm}$ by evaluating 155 patients. Technical success was achieved in $83.4 \%$ for RFA vs. in $86.7 \%$ for MWA. Moreover there was no significant difference in the 1-, 3-, and 5-year overall survival and the 1-, 3-, and 5-year disease-free survival rates between the RFA and MWA groups.

Even in relatively large HCCs, technical success can be achieved. Contrast-enhanced ultrasound (CEUS)-guided MWA was performed by Liu F et al. [40] in 107 patients with large HCCs (mean maximum diameter: $19.5 \pm 8.5 \mathrm{~mm}$ ) with a technical success rate of $98.13 \%$. Regarding comparative evaluation of MWA vs. transarterial chemoembolization (TACE) in large HCCs, Abdelaziz et al. analyzed 64 patients with large HCCs [41]. MWA showed higher rates of complete ablation (75\%) with fewer sessions and a lower incidence of tumor recurrence $(p=0.02)$ with 13.7 months of survival. In summary, MWA showed better results in comparison to TACE alone even in large HCCs [6].

Huang $\mathrm{H}$ et al. [42] retrospectively assessed 136 patients with HCC adjacent to the gallbladder who underwent US-guided percutaneous MWA. They were followed up for a median period of 30.1 months. In all patients two sessions were performed. In case of incomplete ablation, percutaneous ethanol injection (PEI) and other therapies were performed. They concluded that US-guided percutaneous MWA in combination with PEI is a safe and effective treatment option for HCC adjacent to the gallbladder. MWA can be considered as an alternative to RFA, especially when the tumor is located in the vicinity of large vessels. Furthermore, several other studies showed similar results in terms of local tumor control. In a study with 102 patients, Lu et al. reported a technical success rate of $95 \%$ for MWA compared to $93 \%$ for RFA [53].

89 patients with $\mathrm{HCC}$ were compared retrospectively in two groups by Ginsburg M. et al. [43]. The outcomes and complica- 
tions of TACE with drug-eluting embolic agents combined with RFA or MWA were evaluated. Complete local tumor control was $80.4 \%$ in patients treated with TACE combined with RFA and $76.6 \%$ in TACE combined with MWA. The median tumor PFS and overall PFS were 20.8 months and 9.3 months for TACE combined with RFA and 21.8 months and 9.2 months for TACE combined with MWA, respectively. Moreover, the median overall survival (OS) was 23.3 months in the RF group and 42.6 months in the MWA group.

In a prospective study 94 patients with $\mathrm{HCC} \leq 7 \mathrm{~cm}$ underwent RFA or MWA combined with TACE or alone. Combination therapy in the treatment of $\mathrm{HCC} \leq 7 \mathrm{~cm}$ was superior to RFA or MWA alone regarding survival by reducing arterial and portal blood flow due to embolization with iodized oil via TACE before ablation [9].

The data for laparoscopic or intra-operative MWA are rather limited. Cillo $U$ et al. described a laparoscopic MWA technique combined with portal vein ligation for staged hepatectomy [44]. Laparoscopic MWA was successfully applied in patients with multiple colorectal liver metastases and single HCC nodules.

Itoh $S$ et al. [14] described 143 cases of surgical MWA for unresectable initial and recurrent HCC performed in 60 patients. The median follow-up period was 19 months. The 1-, 3-, and 5-year overall survival rates after the surgical MW procedure were 93.9, 53.8 , and $43.1 \%$, respectively.

Ai-Xue Sun et al. retrospectively reviewed 182 patients with a single medium-sized HCC, who underwent percutaneous MWA. The estimated technical rate of effectiveness was $93 \%$. The major complication rate including liver abscess in 4 patients was $2.7 \%$ and abdominal bleeding at the puncture site was seen in one patient. In their study one patient died due to liver abscess-related septicemia (30-day mortality rate $0.5 \%$ ). The cumulative recurrence-free survival and overall survival (OS) rates at 1, 2 and 3 years were $51 \%, 36 \%, 27 \%$ and $89 \%, 74 \%, 60 \%$, respectively [ 45 ].

Medhat E. et al. evaluated US-guided MWA in large HCCs (5$7 \mathrm{~cm}$ ) in 26 patients. According to the size of the lesion, multiple needle insertions were performed in one or two sessions resulting in complete ablation in about $73 \%$ of cases. Local tumor progression was $19.2 \%$ and distant tumor progression within the liver was $23.1 \%$ with a mean survival of 21.5 months. No major complications or deaths related to the procedure were recorded [46].

In a bilateral tumor, a combination of MWA and TACE or surgery can achieve better tumor debulking and better survival rates. However, compared to surgery, MWA has significantly more recurrence rates, which for HCC is about $13.1 \%$ at 1 year after the treatment and $21.1 \%$ at 3 years [47]. It should be considered that incomplete ablations and larger lesions could theoretically lead to an increased recurrence rate of liver tumors. Dong et al. retrospectively compared the safety and efficacy of RFA versus MWA for the treatment of localized HCC and found no significant difference between RFA and MWA [48].

In general, the technical success rate for MWA of HCC ranged between 86.7 - $95 \%$. Progression-free survival rates of up to $91.7 \%$ for small lesions treated with MWA have been described. The 1-, 3- and 5-year survival following MWA ranged between $89-93.9 \%, 53.8-74 \%$ and $43.1-60 \%$ respectively.

\section{MWA results in liver metastases}

In oligonodular liver metastases, the indication for MWA is unresectability or central position of metastases ( $\downarrow$ Fig. 2). Patients with up to 5 liver metastases and a size of $\leq 4 \mathrm{~cm}$ are eligible candidates for local ablation. As previously mentioned, comparable survival results to surgical resection can be reached using different ablation techniques for colorectal cancer liver metastases [23]. In a retrospective analysis Eng et al. treated 49 tumors (0.5 to $5.5 \mathrm{~cm}$ in size) in 33 patients who underwent intraoperative MWA of colorectal cancer liver metastases [49]. Tumor recurrence was documented in 13 patients. The median time to first recurrence was 364 days. The overall survival was $35.2 \%$ at 4 years with a disease-free survival of $19.3 \%$ at 3.5 years.

In a 9-year retrospective analysis of 64 patients with single metastases who underwent MWA, Alexander ES et al. [22] reported a technical success rate of $95 \%$. They included a large spectrum of metastatic lesions including colorectal cancer, breast cancer, carcinoid, melanoma, lung cancer and anal cancer. There was no statistically significant relationship between time to recurrence and tumor size, number of activations, number of antennas, and treatment time. Regarding the local recurrence at 1 year after ablation there was a recurrence of $45.7 \%$ in colorectal metastases and $70.8 \%$ in other metastases compared to $39.8 \%$ in HCC. Furthermore, the 30 -day post-ablation mortality rate was $0 \%$ with no procedure-related deaths. The rate of complications including nausea, pain requiring analgesics, pneumothorax, and pneumonia, which according to SIR classifications are A-D complications, was $23.4 \%$. The survival rates were 36.3 months for colorectal cancer metastases, and 13.9 months for other histological types compared to 38.3 months in HCC patients.

In a cohort study of 1136 patients who underwent MWA as treatment for malignant liver tumors, Liang et al. showed that it is a well-tolerated technique with an acceptably low rate of major complications. Major complications can be reduced by using a cooled-shaft antenna and performing fewer MW sessions [13].

Wang $\mathrm{XH}$ et al. retrospectively analyzed 898 primary liver tumors which were treated in 1111 MWA sessions in order to evaluate the major complications of percutaneous cooled-tip MWA in the treatment of liver cancer. The mean tumor diameter and range were $2.5 \pm 1.2 \mathrm{~cm}$ and $0.4-10.0 \mathrm{~cm}$, respectively. They reported 2 deaths because of pulmonary embolism and hepatorenal syndrome, and also 27 major complications including 10 cases of tumor cell seeding [50].

In a case control study with 89 patients, Li M. et al. evaluated the safety and effectiveness of US-guided percutaneous MWA of 96 hepatic lesions adjacent to the diaphragm. For the control group they selected 100 patients with 127 hepatic lesions not adjacent to the diaphragm, with a minimum distance more than $10 \mathrm{~mm}$ from the lesion to the diaphragm and the first or second branch of the hepatic vessels. Complete ablation was achieved in $94.8 \%$ in the study group and $96.9 \%$ in the control group. The local tumor progression rate was $18.8 \%$ in the study group and $16.5 \%$ in the control group with no major complications [51].

In a multicenter study, Livraghi T et al. evaluated 736 patients with 1037 hepatic lesions using a $2.45 \mathrm{GHz}$ generator delivering energy through a cooled miniature-choke MW antenna. 522 

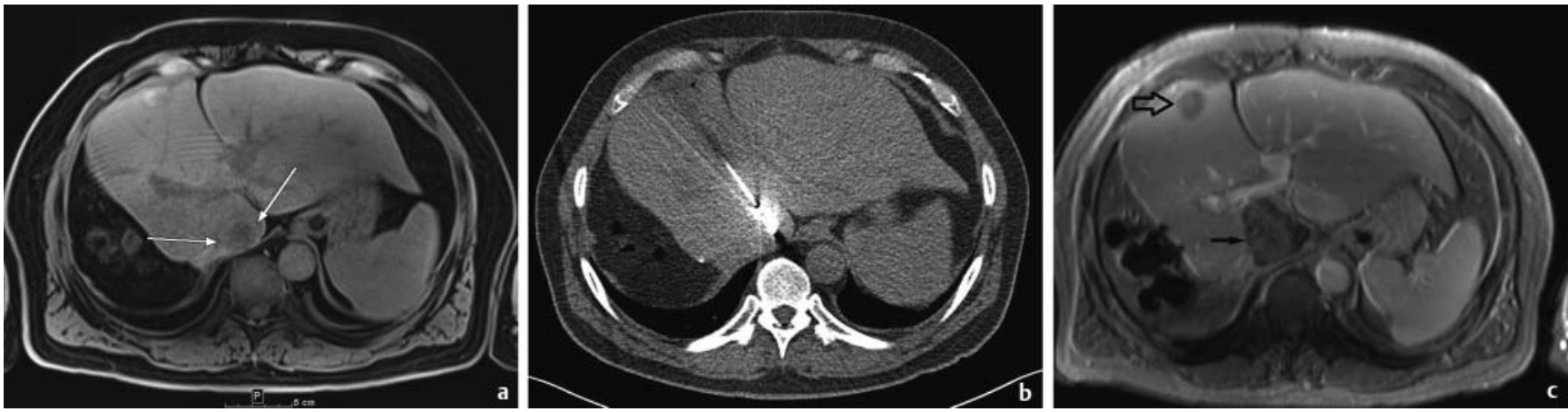

Fig. 2 61-year-old patient with liver metastases of colorectal cancer. Recurrence after previous resection, metachronous liver metastases. Documentation of a metastasis in segment 1 measuring $27 \times 24 \mathrm{~mm}$. Long access to the lesion. a T1w fat saturated sequence. Documentation of the lesion with hypointensity in segment 1. GRE TR/TE 500/17. b CT-guided navigation of an antenna (Amica) directly into the lesion. Thermal ablation with $80 \mathrm{~W}$ for $1 \mathrm{~min}, 100 \mathrm{~W}$ for $1 \mathrm{~min}$ and $120 \mathrm{~W}$ for $6 \mathrm{~min}$. Demonstration of the vaporization of the lesion in the caval structures. c T1w sequence control 6 months after thermal ablation. Demonstration of slight hypointensity of the necrotic tissue. No local complications. No caval compression. The open arrow shows a newly developed metastasis in segment $4 \mathrm{~b}$.

- Abb. 2 61jähriger Patient mit Lebermetastasen bei kolorektalem Karzinom. Rezidiv nach vorheriger Resektion, metachrone Lebermetastasen. Dokumentation einer Metastase in Lebersegment 1 von $27 \times 24 \mathrm{~mm}$. Langer Zugang zur Läsion. a T1-gewichtete fettsaturierte Sequenz. Dokumentation einer hypoerintensen Läsion in Segment 1. GRE TR/TE 500/17. b CT-gesteuerte Nagivation einer Nadel (Amica) directdirekt in die Läsion. Thermoablation mit $80 \mathrm{~W}$ für 1 Min., 100 W für 1 Min. und $120 \mathrm{~W}$ für 6 Min. Vaporisation einer Läsion in den cavalen Strukturen. c T1-gewichtete Sequenz. Kontrolle 6 Monate nach Ablation. Leichte Hypontensität des nekrotischen Gewebes. Keine lokalen Komplikationen. Keine cavale Kompression. Der offene Pfeil weist auf eine neue aufgetretene Metastase im Segment $4 \mathrm{~b}$ hin.

HCCs with cirrhosis, 187 metastases of colorectal cancer and 27 cholangiocellular carcinomas ranging from 0.5 to $10 \mathrm{~cm}$ were included in the study. The rate of major complications was $2.9 \%$ and the rate of minor complications was $7.3 \%$ with no significant difference with respect to RFA, both based on heat damage. They confirmed MWA as a safe procedure for the treatment of hepatic lesions [52].

\section{Summary}

Thermal ablation techniques such as RFA and MWA in the treatment of HCC are now widely accepted as a first-line treatment for very early HCC, inoperable HCC and oligonodular liver metastases especially $\leq 3 \mathrm{~cm}$. There is sufficient data to support the use of MWA for liver metastases from colorectal cancer origin. MWA has also been used to treat a large variety of solid tumor liver metastases. However, large studies addressing each tumor entity are still lacking.

Although in guidelines for HCC (BCLC or AASLD) either ablation or RFA is recommended, studies show that MWA is a promising interventional technique for the control of liver lesions and not only has comparable local control rates and similar survival rates to RFA, but also has some advantages over RFA (less sensitive to "heat-sink effect", faster ablation, greater ablation zones). The advantages of MWA make this method a good treatment option even in inoperable liver tumors with lower morbidity and mortality and the cost is comparable to that of surgery.

The current literature shows that the major advantages of MWA over RFA are less influence by the heat-sink effect of blood vessels adjacent to or embedded in the ablation zone and a faster ablation procedure. Additionally MWA provides less variability and greater predictability in hepatic ablation zones. New develop- ments include antenna placement using a CT-guided stereotactic navigation system. The main advantage here is the improved accuracy and the almost lack of a need to reposition the antenna.

In conclusion, MWA is a promising treatment option for HCC and other secondary liver metastases.

\section{Conflict of Interest}

The authors declare that they have no conflict of interest.

\section{References}

[1] Boyle P, Levin B (eds) Liver Cancer World Cancer Report. IACR Press. 2008: $350-357$

[2] Liu LX, Zhang WH, jiang HC. Current treatment for liver metastases from colorectal cancer. World J Gastroenterol 2003; 9: 193-200

[3] Vogl TJ, Panahi B, Fischer $S$ et al. Interventional therapy of lung and liver metastases. Onkologe, Springer-Verlag: Berlin Heidelberg, 2014

[4] Ahmed M. Image-Guided Tumor Ablation: Standardization of Terminology and Reporting Criteria - A 10-Year Update. RSNA 2014. J Vasc Interv Radiol 2014; 25: $1706-1708$

[5] Lahat E, Eshkenazy R, Zendel A et al. Complications of ablation of liver tumors: a systematic review. Hepatobiliary Surgery and Nutrition 2014; 3: $317-323$

[6] Tabuse K, Katsumi M, Kobayashi Y et al. Microwave surgery: hepatectomy using a microwave tissue coagulator. World J Surg 1985; 9: 136 143

[7] Liang P, Wang Y. Microwave ablation of hepatocellular carcinoma. Oncology Suppl 2007; 72 (Suppl. 1): 124-131

[8] Facciorusso A, Di Maso M, Muscatiello N. Microwave ablation versus radiofrequency ablation for the treatment of hepatocellular carcinoma: A systematic review and meta-analysis. Int J Hyperthermia 2016; 32: $339-344$ 
[9] Yi Y, Zhang Y, Wei Q et al. Radiofrequency ablation or microwave ablation combined with transcatheter arterial chemoembolization in treatment of hepatocellular carcinoma by comparing with radiofrequency ablation alone. Chin J Cancer Res 2014; 26: 112 -8

[10] Goldberg SN, Gazelle GS, Mueller PR. Thermal ablation therapy for focal malignancy: a unified approach to underlying principles, techniques, and diagnostic imaging guidance. Am J Roentgenol 2000; 174: 323 331

[11] Sun Y, Cheng Z, Dong L et al. Comparison of temperature curve and ablation zone between 915- and 2450-MHz cooled-shaft microwave antenna: results in ex vivo porcine livers. European Journal of Radiology 2012; 81: $553-557$

[12] Yang D, Converse MC, Mahvi DM et al. Measurement and Analysis of Tissue Temperature During Microwave Liver Ablation. IEEE Trans Biomed Eng 2007; 54: $150-155$

[13] Liang P, Wang Y, Yu X et al. Malignant liver tumors: treatment with percutaneous microwave ablation-complications among cohort of 1136 patients. Radiology 2009; 251: $933-940$

[14] Itoh S, Ikeda Y, Kawanaka $\mathrm{H}$ et al. Efficacy of surgical microwave therapy in patients with unresectable hepatocellular carcinoma. Ann Surg Oncol 2011; 18: $3650-3656$

[15] Li X, Zhang L, Fan W et al. Comparison of microwave ablation and multipolar radiofrequency ablation, both using a pair of internally cooled interstitial applicators: results in ex vivo porcine livers. Int J Hyperthermia 2011; 27: $240-248$

[16] Poulou LS, Botsa E, Thanou I et al. Percutaneous microwave ablation vs. radiofrequency ablation in the treatment of hepatocellular carcinoma. World J Hepatol 2015; 7: 1054-1063

[17] Yu NC, Lu DS, Raman SS et al. Hepatocellular carcinoma: microwave ablation with multiple straight and loop antenna clusters - pilot comparison with pathologic findings. Radiology 2006; 239: 269-275

[18] Ping Liang, Jie Yu, Ming-De Lu et al. Practice guidelines for ultrasoundguided percutaneous microwave ablation for hepatic malignancy. World J Gastroenterol 2013; 19: 5430-5438

[19] Foltz G. Image-guided percutaneous ablation of hepatic malignancies. Semin Intervent Radiol 2014; 31: 180-186

[20] de Baere T, Tselikas L, Yevich S et al. The role of image-guided therapy in the management of colorectal cancer metastatic disease. Eur J Cancer 2017; 23: $231-242$

[21] Barral M, Auperin A, Hakime A et al. Percutaneous Thermal Ablation of Breast Cancer Metastases in Oligometastatic Patients. Cardiovasc Intervent Radiol 2016; 39: 885 -893

[22] Alexander ES, Wolf FJ, Machan JT et al. Microwave ablation of focal hepatic malignancies regardless of size: A 9-year retrospective study of 64 patients. Eur J Radiol 2015; 84: $1083-1090$

[23] Shibata T, Niinobu T, Ogata N et al. Microwave coagulation therapy for multiple hepatic metastases from colorectal carcinoma. Cancer 2000; 89: $276-284$

[24] Ziemlewicz T], Hinshaw JL, Lubner MG et al. Percutaneous microwave ablation of hepatocellular carcinoma with a gas-cooled system: initial clinical results with 107 tumors. J Vasc Interv Radiol 2015; 26: 62 - 68

[25] Vogl T], Zegelman A, Bechstein WO et al. Treatment of liver metastases of colorectal carcinoma: overview of hyperthermal ablation methods. Dtsch Med Wochenschr 2013; 138: $792-798$

[26] Moreland AJ, Lubner MG, Ziemlewicz T] et al. Evaluation of a Thermoprotective Gel for Hydrodissection During Percutaneous Microwave Ablation: In Vivo Results. Cardiovasc Intervent Radiol 2014 2015; 38 : $722-730$

[27] Chen EA, Neeman Z, Lee FT et al. Thermal protection with 5\% dextrose solution blanket during radiofrequency ablation. Cardiovasc Interv Radiol 2006; 29: $1093-1096$
[28] Yamakado K, Nakatsuka A, Akeboshi M et al. Percutaneous radiofrequency ablation of liver neoplasms adjacent to the gastrointestinal tract after balloon catheter interposition. J Vasc Interv Radiol 2003; 14 : $1183-1186$

[29] Park BK, Kim CK. Using an electrode as a lever to increase the distance between renal cell carcinoma and bowel during CT-guided radiofrequency ablation. Eur Radiol 2008; 18: $743-746$

[30] Zhang M, Liang P, Cheng ZG et al. Efficacy and safety of artificial ascites in assisting percutaneous microwave ablation of hepatic tumors adjacent to the gastrointestinal tract. Int J Hyperthermia 2014; 30: 134-41

[31] Stone M], Wood B]. Emerging local ablation techniques. Semin Intervent Radiol 2006; 23: 85-98

[32] Sainani NI, Gervais DA, Mueller PR et al. Imaging after percutaneous radiofrequency ablation of hepatic tumors. I. Normal findings. Am J Roentgenol 2013; 200: 184-193

[33] Wang X, Sofocleous CT, Erinjeri JP et al. Margin size is an independent predictor of local tumor progression after ablation of colon cancer liver metastases. Cardiovasc Intervent Radiol 2013; 36: 166-175

[34] Kim YS, Lee WJ, Rhim $\mathrm{H}$ et al. The minimal ablative margin of radiofrequency ablation of hepatocellular carcinoma $(<2$ and $<5 \mathrm{~cm})$ needed to prevent local tumor progression: 3D quantitative assessment using CT image fusion. Am J Roentgenol 2010; 195: 758-765

[35] Sacks D, McClenny TE, Cardella JF et al. Society of Interventional Radiology clinical practice guidelines. J Vasc Interv Radiol 2003; 14: S199 S202

[36] Davis CR. Interventional radiological treatment of hepatocellular carcinoma. Cancer Control 2010; 17: 87-99

[37] Huo YR, Eslick GD. Microwave Ablation Compared to Radiofrequency Ablation for Hepatic Lesions: A Meta-Analysis. J Vasc Interv Radiol 2015; 26: $1139-1146$

[38] Vogl T], Farshid P, Naguib NNN et al. Ablation therapy of hepatocellular carcinoma: a comparative study between radiofrequency and microwave ablation. Abdominal Imaging 2015; 40: 1829-1837

[39] Zhang L, Wang N, Shen Q et al. Therapeutic efficacy of percutaneous radiofrequency ablation versus microwave ablation for hepatocellular carcinoma. PLoS One 2013; 8: e76119

[40] Liu F, Yu X, Liang P et al. Contrast-enhanced ultrasound-guided microwave ablation for hepatocellular carcinoma inconspicuous on conventional ultrasound. Int J Hyperthermia 2011; 27: 555-562

[41] Abdelaziz AO, Nabeel MM, Elbaz TM et al. Microwave ablation versus transarterial chemoembolization in large hepatocellular carcinoma: prospective analysis. Scandinavian Journal of Gastroentereology 2015; 50: $479-484$

[42] Huang $H$, Liang $P, Y u X L$ et al. Safety assessment and therapeutic efficacy of percutaneous microwave ablation therapy combined with percutaneous ethanol injection for hepatocellular carcinoma adjacent to the gallbladder. Int J Hyperthermia 2015; 31: 40-47

[43] Ginsburg M, Zivin SP, Wroblewski K et al. Comparison of Combination Therapies in the Management of Hepatocellular Carcinoma: Transarterial Chemoembolization with Radiofrequency Ablation versus Microwave Ablation. J Vasc Interv Radiol 2015; 26: 330-341

[44] Cillo U, Gringeri E, Feltracco P et al. Totally Laparoscopic Microwave Ablation and Portal Vein Ligation for Staged Hepatectomy. Ann Surg Oncol 2015; 22: 2787 - 2788 doi: 10.1245/s10434-014-4353-7

[45] Ai-Xue Sun, Zhi-Li Cheng, Pan-Pan Wu et al. Clinical outcome of medium-sized hepatocellular carcinoma treated with microwave ablation. World J Gastroenterol 2015; 21: 2997 - 3004

[46] Medhat E, Abdel AzizA, Nabeel M et al. Value of Microwave Ablation in Treatment of large lesions of Hepatocellular Carcinoma. J Dig Dis 2015; 16: $456-463$

[47] Ohmoto K, Yoshioka N, Tomiyama Y et al. Radiofrequency ablation versus percutaneous microwave coagulation therapy for small hepatocel- 
lular carcinomas: a retrospective comparative study. Hepatogastroenterology 2007; 54: 985-989

[48] Dong B, Liang P, Yu X et al. Percutaneous sonographically guided microwave coagulation therapy for hepatocellular carcinoma: results in 234 patients. Am J Roentgenol 2003; 180: 1547-1555

[49] Eng OS, Tsang AT, Moore D et al. Outcomes of Microwave Ablation for Colorectal Cancer Liver Metastases: A Single Center Experience. Journal of Surgical Oncology 2015; 111: 410-413

[50] Wang XH, Yu J, Liang P et al. Percutaneous cooled-tip microwave ablation under ultrasound guidance for primary liver cancer: analysis of major complications in 693 patients. Zhonghua Zhong Liu ZaZhi 2012; 34: 945 - 949
[51] Li M, Yu XL, Liang P et al. Percutaneous microwave ablation for liver cancer adjacent to the diaphragm. Int J Hyperthermia 2012; 28: 218 226

[52] Livraghi T, Meloni F, Solbiati L et al. Collaborative Italian Group using AMICA system. Complications of microwave ablation for liver tumors: results of a multicenter study. Cardiovasc Intervent Radiol 2012; 35: $868-874$

[53] Lu MD, Xu HX, Xie XY et al. Percutaneous microwave and radiofrequency ablation for hepatocellular carcinoma: a retrospective comparative study. J Gastroenterol 2005; 40: 1054-1060

[54] Groeschl RT, Pilgrim CH, Hanna EM et al. Microwave ablation for hepatic malignancies: a multiinstitutional analysis. Ann Surg 2014; 259: 1195 1200 